This item was submitted to Loughborough's Research Repository by the author.

Items in Figshare are protected by copyright, with all rights reserved, unless otherwise indicated.

\title{
Alzheimer: nasal transplantation of microglia
}

PLEASE CITE THE PUBLISHED VERSION

http://dx.doi.org/10.1016/j.exger.2015.01.010

\section{PUBLISHER}

(c) Elsevier

\section{VERSION}

AM (Accepted Manuscript)

\section{PUBLISHER STATEMENT}

This work is made available according to the conditions of the Creative Commons Attribution-NonCommercialNoDerivatives 4.0 International (CC BY-NC-ND 4.0) licence. Full details of this licence are available at: https://creativecommons.org/licenses/by-nc-nd/4.0/

\section{LICENCE}

CC BY-NC-ND 4.0

\section{REPOSITORY RECORD}

Fabian, Claire, Yahaira Naaldijk, and Alexandra Stolzing. 2019. "Alzheimer: Nasal Transplantation of Microglia". figshare. https://hdl.handle.net/2134/20648. 


\section{Transplantation of in vitro derived microglia}

Alzheimer's disease (AD) is an age-related neurodegenerative disease associated with the formation of amyloid plaques, tau aggregation and oxidative/inflammatory damage. Microglia play an important role in the early phase of the disease and are known to be involved in $A D$ progression. Senescent microglia accumulate in $A D$ causing inflammation, neuronal damage and increasing the $A ß$ load. Microglia could be an attractive target for mesenchymal cell therapies (MSC).

Bone marrow derived MSC were injected into the tail vein of APP/PS1 Alzheimer mice ( 12 months).

After 4 weeks recipient animals and controls were sacrificed, brain tissue was isolated and examined by immunohistochemistry and PCR for amyloid pathology, distribution of transplanted cells and inflammation markers.

Microglia and astrocyte morphology and activation status was analysed using histology and stereology for quantification of changes and we found a significant reduction in medium sized amyloid plaque size and a decrease in microglia activation. Stereology was also used to quantify the reduction of amyloid plaque numbers and size. Expression of various inflammatory genes was analysed via PCR and many were down-regulated after MSC transplantation. 

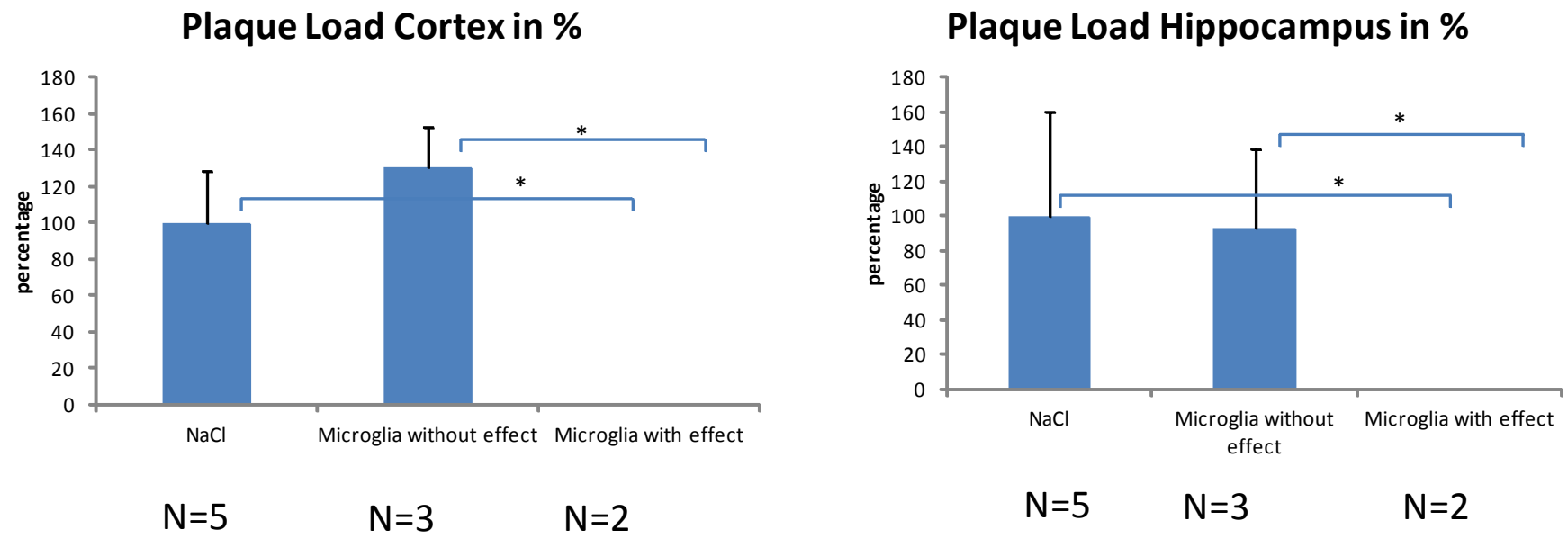

Fig.1 Sterological analysis of amyloid amount in cortex and hippocampus in Alzheimer mice after systemic injection of in vitro differentiated young microglia. Two animals showed total elimination of amyloid and three had normal levels of plaques. PCR analysis revealed that these mice had lower levels of $y$-chromosome signal in the brain tissue (less cells transplanted).

In the moment it is not fully understood if there are mice which do not respond to the therapy or if it is a problem of cell delivery (injection into mice tail is difficult even for well trained people. We are in the moment controlling if and how many cells are found in these "non-responders".
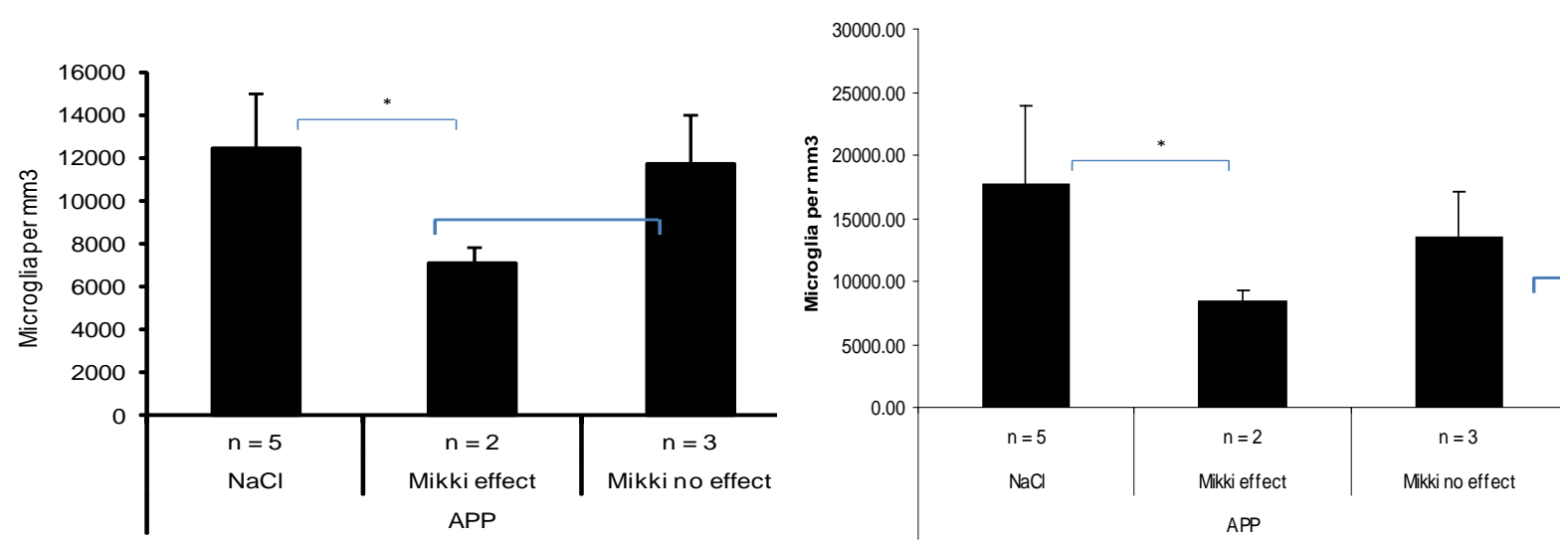

Fig.2 Sterological analysis of microglia numbers in cortex and hippocampus in Alzheimer mice after systemic injection of in vitro differentiated young microglia. Two animals showed a significant reduction of microglia numbers.

With the sterological analysis all microglia are counted including brain microglia and transplanted microglia. It is known that microglia proliferate in response to amyloid exposure in vitro. The theory in the moment is that animals with no amyloid do not have the microglia proliferation signal.

We have performed the same experiments using MSC and found the same reduction. We did not control the efficacy of the therapy using irradiated hepatocytes or other cells where one can speculate that they do not induce a therapeutic response as the main goal is that the pathology is reduced and that memory is restored. 
Microglia transplantation
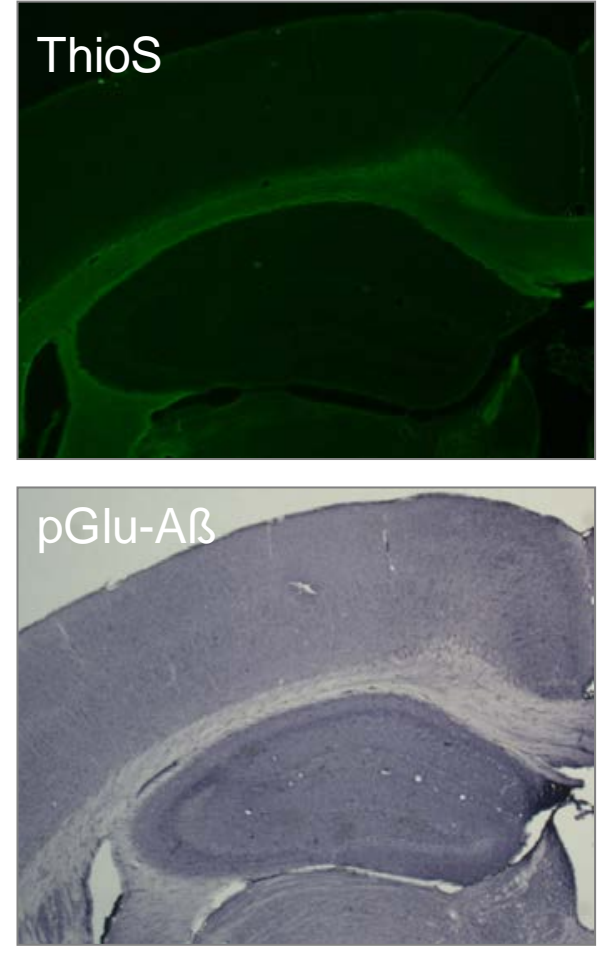

$\mathrm{NaCl}$ controls
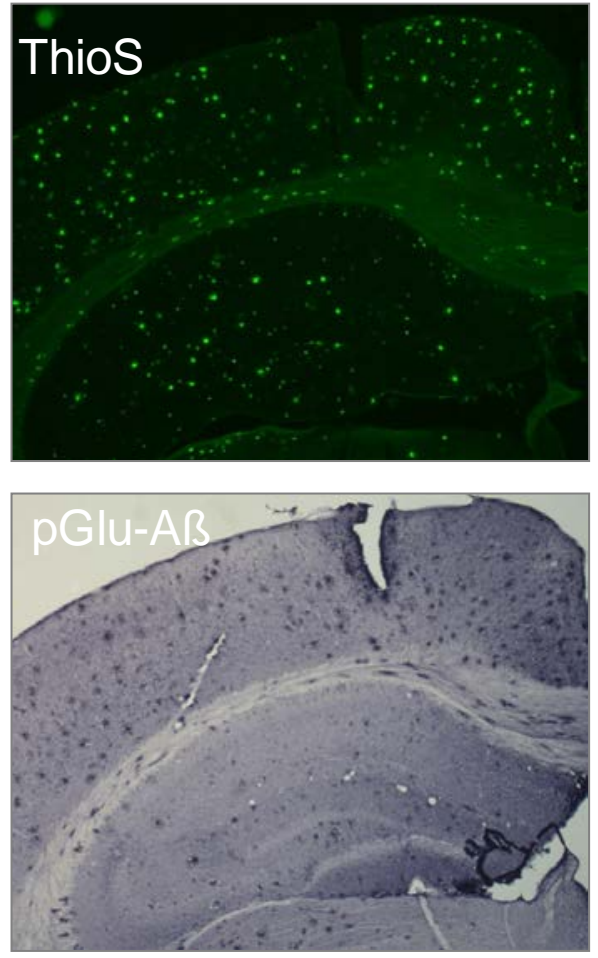

Fig.3 Brain tissue stained with Thioflavin S staining amyloid and pGlu-Aß a modified amyloid beta discussed to be an seed for amyloid plaques.

\section{$\mathrm{NaCl}$ controls}
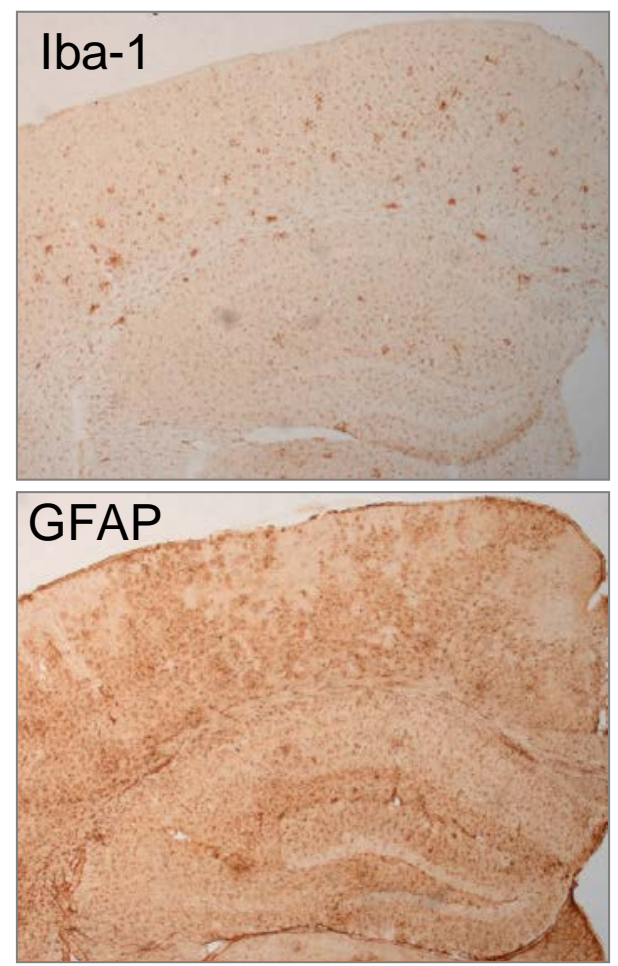

\section{Microglia transplantation}

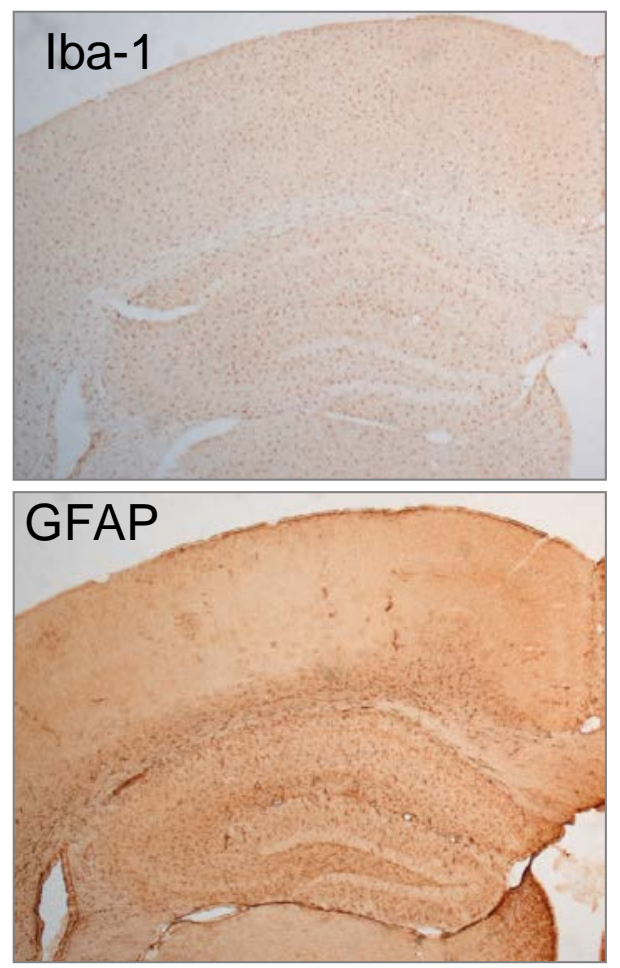

Fig.3 Brain tissue stained for microglia (iba-1), which cluster around amyloid plaques (dark spots) and astrocytes (GFAP). 
Transplanted cells are derived from mice of the same background. It is not a syngenic transplantation but both are inbreed lines of the same type. The immune rejection is minimal. In addition it is known that macrophages can be also immune-modulatory and are sometimes also not rejected.

Differences between microglia and macrophages are still widely discussed. Some publications define microglia to be expressing CD45medium and CD11b high and macrophages are CD45 high and CD11b high. We compared our in vitro differentiated cells to primary isolated microglia and find them to be similar in these and other microglia markers. 